\title{
High yield synthesis of carbon nanofibers in an environmental friendly route
}

\author{
R. Ravindra • Bhat Badekai Ramachandra
}

Received: 18 March 2011/Accepted: 3 June 2011/Published online: 22 June 2011

(C) The Author(s) 2011. This article is published with open access at Springerlink.com

\begin{abstract}
An environmental friendly route for the high yield synthesis of carbon nanofibers (CNFs) has been developed. CNFs have been synthesized using nickel formate as catalyst precursor at $680^{\circ} \mathrm{C}$ using chemical vapor deposition method. Upon pyrolysis this catalyst precursor yields metal catalyst nanoparticles directly. The sodium chloride and potassium chloride was used as catalyst support, it was chosen because of its non-toxic and water soluble nature. The problems such as detrimental effect, environment and even cost has been avoided by using water soluble supports. The structure of the products was characterized by scanning electron microscopy, transmission electron microscopy, Raman spectroscopy and X-ray diffraction method. The purity of as grown products and purified products was determined by thermal analysis. Here, we report the 7,800 and 7,200 wt\% yield of CNFs synthesized over $\mathrm{NaCl}$ and $\mathrm{KCl}$ support. This synthetic route can be used for the large scale synthesis in industries.
\end{abstract}

Keywords Carbon nanofibers - Water soluble substrates · Chemical vapor deposition · Environmental friendly method

\section{Introduction}

Since the discovery of carbon nanotubes by Iijima (1991), an intensive research has been carried out on carbon nanofibers (CNFs) and carbon nanotubes (CNTs). These

R. Ravindra · B. Badekai Ramachandra ( $\square)$

Catalysis and Materials Division, Department of Chemistry,

National Institute of Technology, Surathkal, Mangalore 575025,

Karnataka, India

e-mail: chandpoorna@yahoo.com materials have unique mechanical, chemical and electrical properties and hence attracted many researchers. CNTs and CNFs have large number of potential applications which include field emission sources (Milne et al. 2004), hydrogen storage (Dillon et al. 1997), catalyst substrate (Bahome et al. 2005), chemical sensors (Douglas and Alexander 2010), scanning probe tip (Demicheva et al. 2008), electrode material (Jan et al. 2009), nanoelectronics (Brataas 2010) and mechanical reinforcements (Wang et al. 2010). Until now, various synthetic methods have been developed for the production of these nanostructures, including arc discharge (Iijima 1991), laser vaporization (Guo et al. 1995) and chemical vapor deposition (CVD) (Baker et al. 1989; Su et al. 2000). One of the remarkable advantages of CVD method is that it produces cheap CNTs and CNFs with high yields. The choice of the supporting material has been found to be important factor to synthesize these carbon nanostructures by CVD method. The support materials such as silica, alumina or magnesia are widely studied (Nagaraju et al. 2002; Kathyayini et al. 2008; Bris et al. 2010; Seifi 2011). But these supports are soluble in acids and hence acid wash is required to separate these supports from carbon structures after growth. The acid wash causes detrimental effect, environment problems and effects cost efficiency. Therefore, an important approach for the largescale production of high quality CNTs or CNFs is (1) to avoid acids for purification and (2) to reduce the number of purification steps. In this paper, we have developed novel method to synthesize CNFs by CVD method using water soluble substrates. Nickel formate is used as catalyst precursor, as it directly yields metal catalyst nanoparticles on pyrolysis. The main advantage of using nickel formate is that it avoids the lengthy process of reduction and calcination. Sodium chloride and potassium chloride are used as supports, as they are easily soluble in water. The use of 
acid or base is completely avoided by using water soluble substrates. Here, we report the 7,800 wt $\%$ yield of CNFs synthesized over nickel formate as catalyst precursor on $\mathrm{NaCl}$ substrate.

\section{Experimental}

All the reagents used were AR-grade and purchased from Sigma Aldrich. Nickel formate was prepared by nickel acetate and formic acid at $80^{\circ} \mathrm{C}$. The microcrystalline precipitate was obtained on cooling which was filtered,

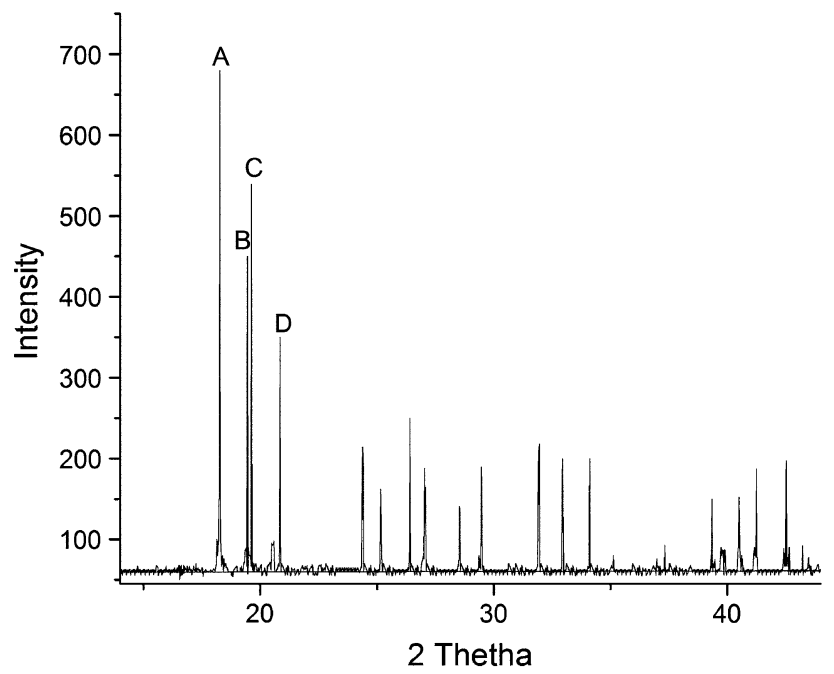

Fig. 1 XRD pattern of nickel formate. Peaks $A, B, C$ and $D$ are the characterisation peaks of nickel formate (JCPDS 14-0813) dried at $100^{\circ} \mathrm{C}$. The formation of nickel formate was confirmed by X-ray diffraction method (Fig. 1). The supported catalyst was made by dispersing the nickel formate catalyst precursor on substrate. The obtained supported catalysts were denoted as $\mathrm{Ni} / \mathrm{NaCl}$ and $\mathrm{Ni} / \mathrm{KCl}$.

In this study, the synthesis of CNFs was carried out at atmospheric pressure in a fixed bed CVD reactor. The length and diameter of quartz tube were 900 and $20 \mathrm{~mm}$, respectively. The detailed experimental set up is shown in the Fig. 2. $300 \mathrm{mg}$ of catalyst precursor with support was taken in quartz boat. The boat was placed in the centre of the quartz tube after the reactor reaches the $680^{\circ} \mathrm{C}$ in an argon atmosphere. Acetylene gas was then released in order to grow the CNFs for $15 \mathrm{~min}$. The reactor was cooled in an argon atmosphere and then carbon deposits were collected. The carbon yield is calculated by Eq. 1

$\frac{M_{\text {Total }}-M_{\text {Cat }}}{M_{\text {Cat }}} \times 100=$ Carbon yield $\%$

where $M_{\text {Total }}$ is the total mass of the carbon product and catalyst, and $M_{\text {Cat }}$ is the mass of the catalyst.

To purify the sample, the raw material was stirred in warm water to remove the catalyst and support. The sample was finally washed with deionized water and dried in oven.

The structure and morphology of the synthesized CNFs were characterized by scanning electron microscope (SUPRA 40VP, Carl Zeiss), transmission electron microscope (CM200, Philips), laser Raman spectrometer (Renishaw, RM 1000, He-Ne laser excitation line at $633.0 \mathrm{~nm}$ ), X-ray diffractometer (JEOL JDX 8P) and thermogravimetry analysis (SDT Q600, TA, USA).
Fig. 2 Schematic representation of CVD set-up. $A$ argon gas cylinder. $B$ acetylene gas cylinder. $C$ quartz tube. $D$ furnace. $E$ quartz boat. $F$ thermocouple. $G$ temperature regulator

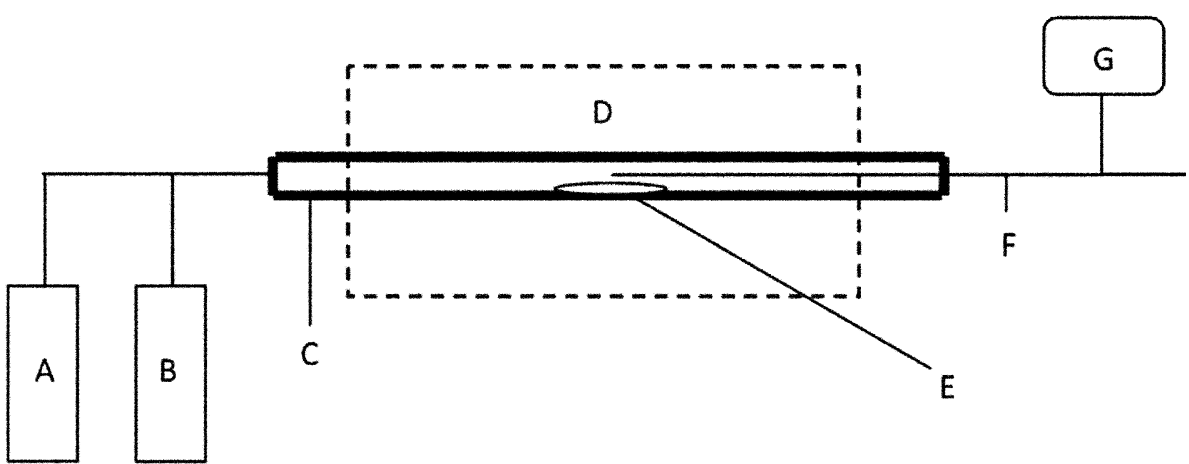

Table 1 Summary of support, wt $\%$ of metal in support, CVD parameters, yields and morphology of carbon nanofibers produced

\begin{tabular}{lllll}
\hline Support & $\begin{array}{l}\text { Metal loading on } \\
\text { support (wt } \%)\end{array}$ & $\begin{array}{l}\text { Gas flow rate }\left(\mathrm{ml} \mathrm{min}^{-1}\right) \\
\text { temperature }\end{array}$ & $\begin{array}{l}\text { Yield } \\
\%\end{array}$ & $\begin{array}{l}\text { Morphology of carbon } \\
\text { nanofibers }\end{array}$ \\
\hline $\begin{array}{r}\text { Sodium } \\
\text { chloride }\end{array}$ & 3 & $\mathrm{C}_{2} \mathrm{H}_{2}=20 \mathrm{Ar}=200$ & 7,800 & $\begin{array}{c}\text { Straight carbon nanofibers, } \\
I_{\mathrm{D}} / I_{\mathrm{G}}=1.005\end{array}$ \\
$\begin{array}{r}\text { Potassium } \\
\text { chloride }\end{array}$ & 3 & $680^{\circ} \mathrm{C}$ & & $\begin{array}{c}\text { Curved carbon nanofibers, } \\
I_{\mathrm{D}} / I_{\mathrm{G}}=1.004\end{array}$ \\
\hline
\end{tabular}




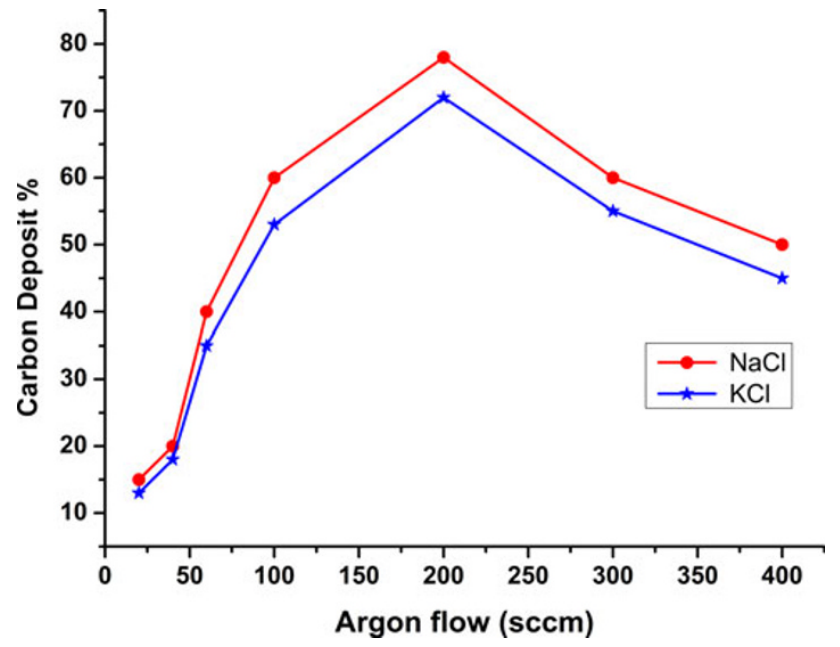

Fig. 3 Chart of amount of carbon deposit with different gas flow of argon $(\mathrm{sccm})$, at constant flow of $20 \mathrm{sccm}$ of acetylene at $680^{\circ} \mathrm{C}$

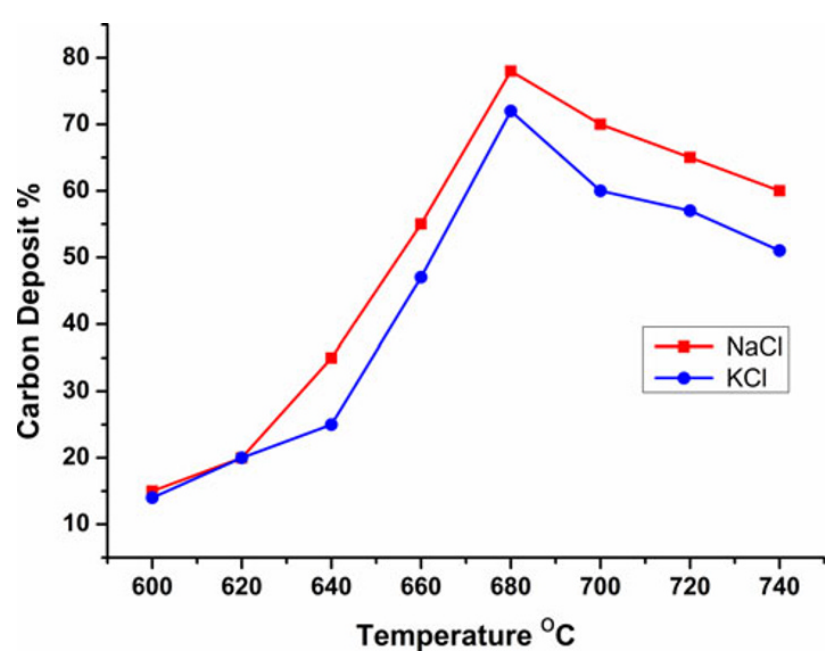

Fig. 4 Chart of amount of carbon deposit with different temperature at gas flow $\left(20 \mathrm{sccm} \mathrm{C}_{2} \mathrm{H}_{2}: 200 \mathrm{sccm} \mathrm{Ar}\right)$

\section{Results and discussion}

In this study, the catalyst precursor with support was introduced after the CVD reactor reaches the $680^{\circ} \mathrm{C}$. The pyrolysis of nickel formate in the gas flow system leads to the formation of nickel nanoparticles. Mechanism of formation of nickel nanoparticles from nickel formate is discussed in the literature (Edwards et al. 1997). The time and cost has been reduced in this process because both calcination and reduction is avoided in the preparation of catalyst. The prepared nickel formate precursor was characterized by X-ray diffraction method. Figure 1 show the XRD pattern of prepared nickel formate. They have characteristic peaks A, B, C and D (JCPDS 14-0813). The Table 1 gives summary of catalyst precursor, wt $\%$ of metal in support, CVD parameters, yields and morphology of CNFs produced.

The melting point of $\mathrm{NaCl}$ is $800^{\circ} \mathrm{C}$, so all the reactions were performed below this temperature. A variety of experiments were conducted with argon-acetylene mixture with various volume ratios $(20: 1,15: 1,10: 1,5: 1,3: 1,2: 1$ and 1:1) at reaction temperatures between 600 and $740^{\circ} \mathrm{C}$ (Figs. 3, 4). The carbon deposit at $680^{\circ} \mathrm{C}$ was maximum. The metal loading percentage was fixed to $3 \mathrm{wt} \%$ in catalyst support in order to avoid sintering effect of catalyst at high temperatures. So all the reaction were performed at $680^{\circ} \mathrm{C}$ with gas flow of $200 \mathrm{sccm}$ : $20 \mathrm{sccm}\left(\mathrm{Ar}: \mathrm{C}_{2} \mathrm{H}_{2}\right)$ for $15 \mathrm{~min}$.

Figure 5 shows the SEM morphologies of purified CNFs grown on nickel formate $/ \mathrm{NaCl}$ and nickel formate $/ \mathrm{KCl}$. Because of their twisting morphology it is difficult to measure the length of the CNFs from the SEM micrographs, but the length can be estimated to be more than several tens of micrometers. As seen in SEM image, the catalytic particles and support were removed successfully by the purification. Structural details of the products were further investigated by TEM. Figure 6 show the TEM
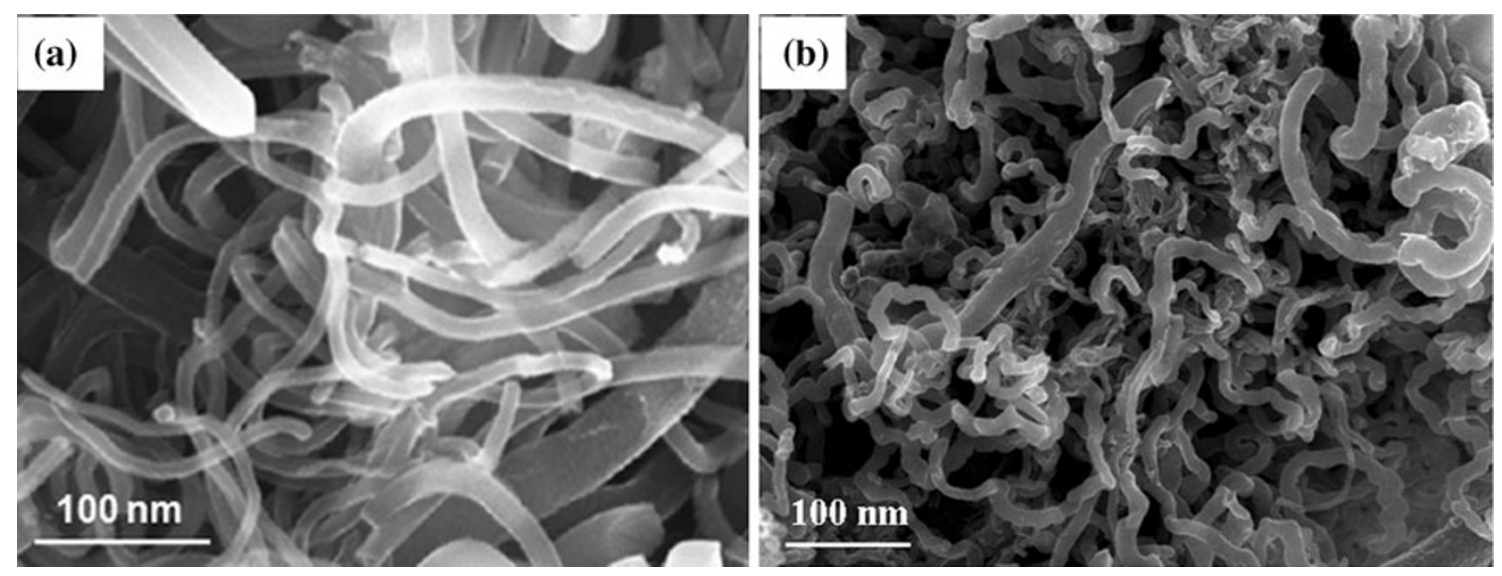

Fig. 5 SEM images of purified $\mathrm{CNFs}$ grown on $\mathbf{a ~} \mathrm{NaCl}, \mathbf{b} \mathrm{KCl}$ by using nickel formate as catalyst precursor

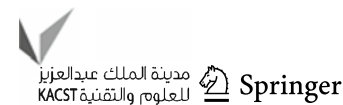


images of the purified CNFs grown on nickel formate/ $\mathrm{NaCl}$ and nickel formate/ $\mathrm{KCl}$. There is clear evidence form TEM micrograph for the formation of CNFs. The diameters of the CNFs are in the range of $10-50 \mathrm{~nm}$.

TGA results in Fig. 7 show the weight loss of CNFs during the oxidation under air atmosphere. The TGA curve in the temperature range of $30-700^{\circ} \mathrm{C}$ shows a total weight loss of $60 \mathrm{wt} \%$ for products grown on nickel formate $/ \mathrm{NaCl}$ and nickel formate $/ \mathrm{KCl}$. There is a little bit of amorphous carbon in our samples because there are negligible mass losses below $400^{\circ} \mathrm{C}$ in the TGA spectrum. According to curve $\mathrm{c}$, the purity of the purified CNFs increases to $99.0 \%$ after purification process.

The representative Raman spectra (Fig. 8) of the samples show the typical features of CNFs. In detail, there exist two strong peaks at 1,592,1,596 $\mathrm{cm}^{-1}$ and $1,328,1,334 \mathrm{~cm}^{-1}$ corresponding to the typical Raman peaks of graphitized carbon. The peak at 1,592 and $1,596 \mathrm{~cm}^{-1}$ is attributed to the Raman-active $\mathrm{E}_{2 \mathrm{~g}}$ in-plane vibration mode and is related to the vibration of $s p^{2}$-bonded carbon atoms in a twodimensional hexagonal lattice. The peak at 1,328 and $1,334 \mathrm{~cm}^{-1}$ is associated with vibrations of carbon atoms with dangling bonds in plane terminations of disordered graphite (Eklund et al. 1995). The intensity of D-band peak

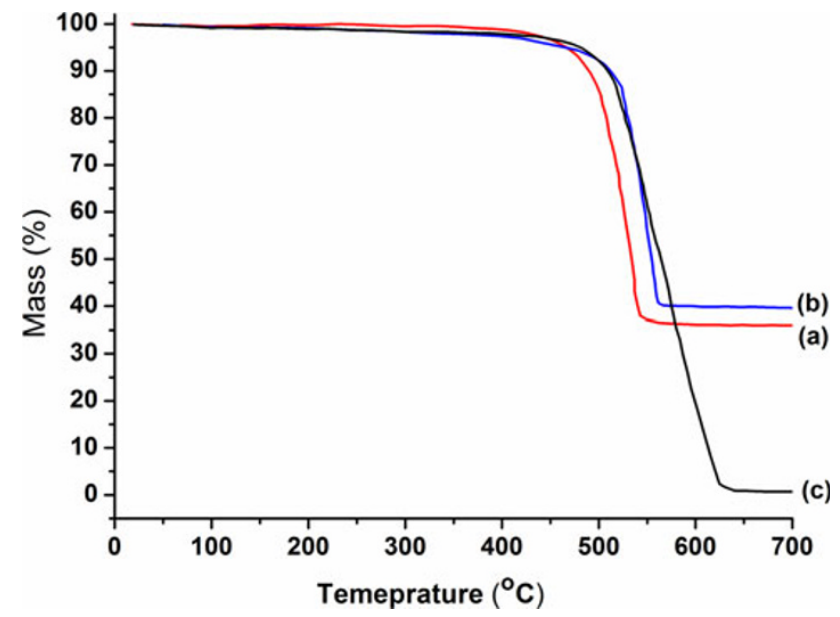

Fig. 7 TGA analysis of yields of CNFs produced on support a $\mathrm{NaCl}$, b $\mathrm{KCl}$ and $\mathbf{c}$ purified CNFs grown on $\mathrm{KCl}$ by using nickel formate as catalyst precursor

is stronger than that of G-band peak, which originates from the in-plane defects of the product preventing the layer from extending.

Figure 9 shows the XRD pattern of the purified samples. It contains two characteristic peaks at about $26.0^{\circ}$ and (a)

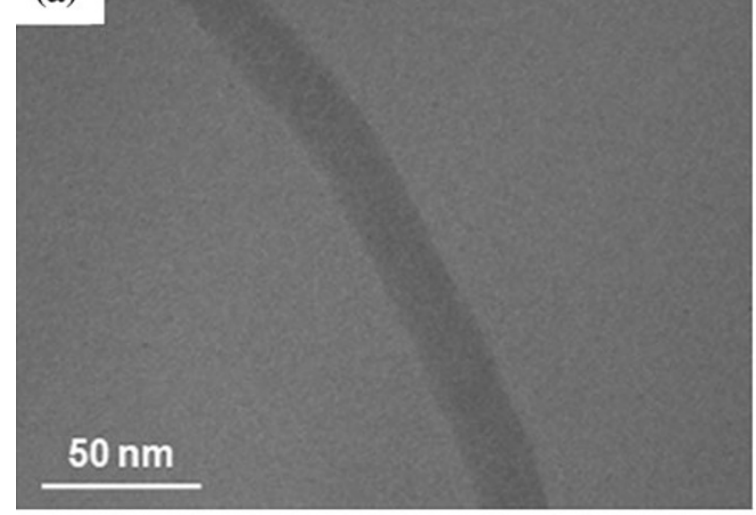

\section{(b)}

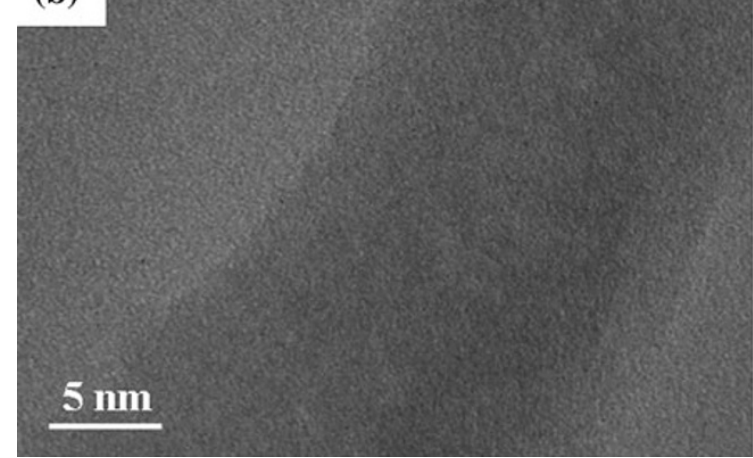

(c)

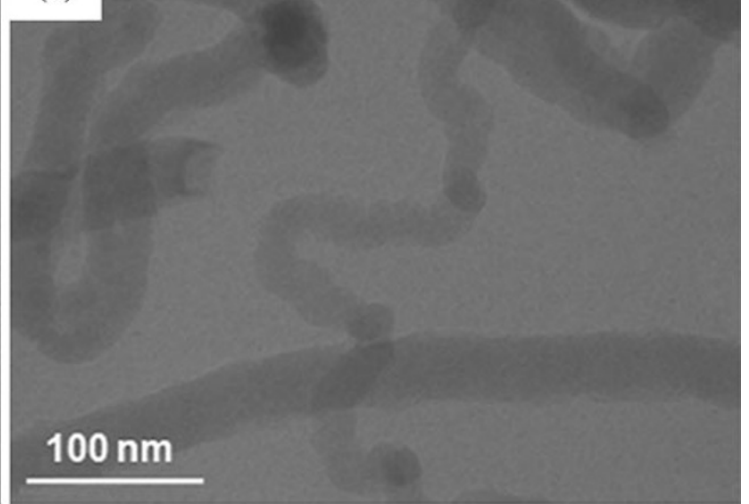

(d)

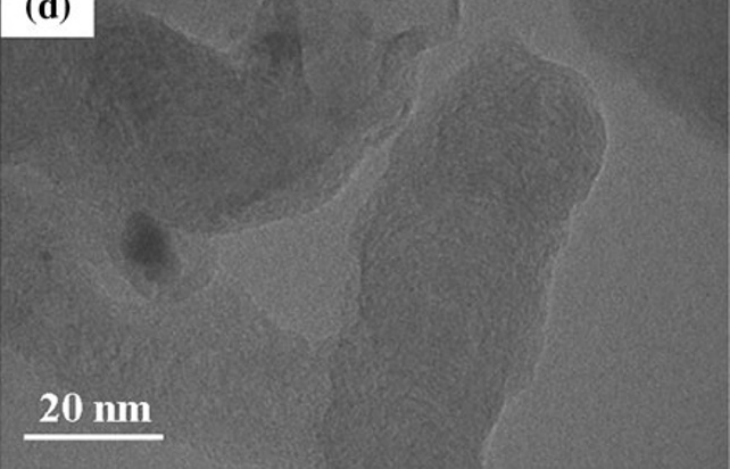

Fig. 6 TEM images of purified CNFs grown on $\mathrm{NaCl}(\mathbf{a}, \mathbf{b})$ and $\mathrm{KCl}(\mathbf{c}, \mathbf{d})$ by using nickel formate as catalyst precursor 


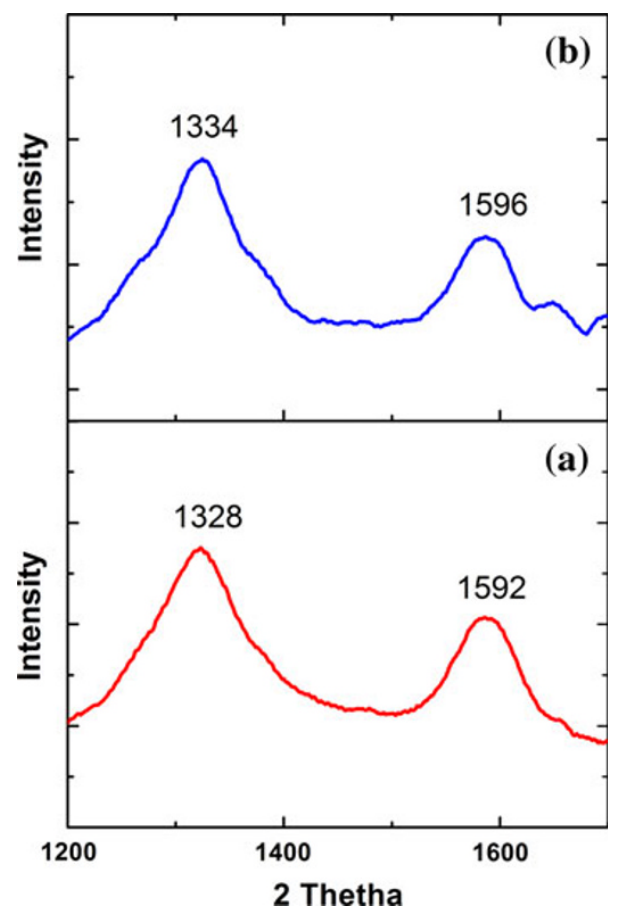

Fig. 8 Raman spectra of purified $\mathrm{CNFs}$ grown on a $\mathrm{NaCl}, \mathbf{b} \mathrm{KCl}$ by using nickel formate as catalyst precursor

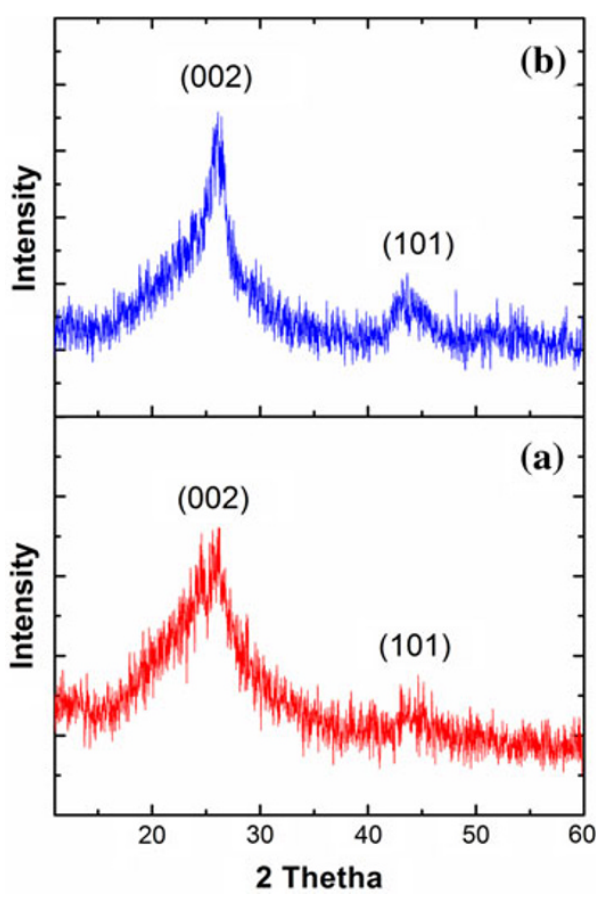

Fig. 9 XRD pattern of purified $\mathrm{CNF}$ grown on a $\mathrm{NaCl}, \mathbf{b} \mathrm{KCl}$ by using nickel formate as catalyst precursor

$43.5^{\circ}$, indexed with 002 and 101 diffraction planes of hexagonal graphite (JCPDS card files, no. 41-1487), respectively. No peaks induced by impurities can be observed in the XRD pattern.

\section{Conclusions}

In this work, we have developed a simple method to synthesize CNFs in the bulk scale by CVD method. Nickel formate was used as catalyst precursor because it forms nickel nanoparticles on pyrolysis. Sodium chloride and potassium chloride which are easily soluble in water and non-toxic are used as supports. The yield of carbon nanofibers is high on sodium chloride support when compare to potassium chloride support. The uses of acid and toxic materials are completely avoided. By this route we can grow CNFs in large scale by using low cost precursors in an economical and environmental friendly way.

Acknowledgments The authors would like to thank Defense Research and Development Organisation (DRDO), Government of India for financial assistance and also SAIF, IITB and Instrumental facility, CECRI for providing analytical services.

Open Access This article is distributed under the terms of the Creative Commons Attribution License which permits any use, distribution and reproduction in any medium, provided the original author(s) and source are credited.

\section{References}

Bahome MC, Jewell LL, Padayachy K, Hildebrandt D, Glasser D, Datye AK, Coville NJ (2005) Fischer-Tropsch synthesis over iron catalysts supported on carbon nanotubes. Appl Catal A 287: 60-67. doi:10.1016/j.apcata.2005.03.029

Baker RTK (1989) Catalytic growth of carbon filaments. Carbon 27:315-323. doi:10.1016/0008-6223(89)90062-6

Biris AR, Dervishi E, Simon S, Lupu D, Misan I, Iancu C, Clichici SV, Xu Y, Watanabe F, Biris AS (2010) Analytic studies of high quality single wall carbon nanotubes synthesized on a novel Fe:Mo:MgO catalyst. Phys E 43:552-558. doi:10.1016/j.physe. 2010.09 .014

Brataas A (2008) Nanoelectronics: spin surprise in carbon. Nature 452:419-420. doi:10.1038/452419a

Demicheva OV, Meshkov GB, Sinitsyna OV, Tomishko AG, Yaminsky IV (2008) Multiwall carbon nanotube tips for scanning probe microscopy. Nanotechnol Russ 3:704-709. doi: 10.1134/S1995078008110062

Dillon AC, Jones KM, Bekkedahl TA, Kiang CH, Bethune DS, Heben MJ (1997) Storage of hydrogen in single-walled carbon nanotubes. Nature 386:377-379. doi:10.1038/386377a0

Douglas RK, Alexander S (2010) Graphene versus carbon nanotubes for chemical sensor and fuel cell applications. Analyst 135:2790-2797. doi:10.1039/C0AN00262C

Edwards AB, Garner CD, Roberts KJ (1997) In situ QXAFS study of the pyrolytic decomposition of nickel formate dihydrate. J Phys Chem B 101:20-26. doi:10.1021/jp961488m

Eklund PC, Holden JM, Jishi RA (1995) Vibrational modes of carbon nanotubes; spectroscopy and theory. Carbon 33:959-972. doi: 10.1016/0008-6223(95)00035-C

Guo T, Nicolaev P, Thess A, Colbert DT, Smalley RE (1995) Catalytic growth of single-walled nanotubes by laser vaporization. Chem Phys Lett 243:49-54. doi:10.1016/0009-2614(95) 00825-O

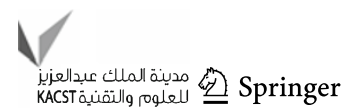


Iijima S (1991) Helical microtubules of graphitic carbon. Nature 354:56-58. doi:10.1038/354056a0

Jan E, Hendricks JL, Husaini L, Burns SMR, Sereno A, Martin DC, Kotov NA (2009) Layered carbon nanotube-polyelectrolyte electrodes outperform traditional neural interface materials. Nano Lett 9:4012-4018. doi:10.1021/n1902187z

Kathyayini H, Reddy KV, Nagy JB, Nagaraju N (2008) Synthesis of carbon nanotubes over transition metal ions supported on $\mathrm{Al}(\mathrm{OH})_{3}$. Indian J Chem (Sec B) 47A:663-668

Milne WI, Teo KBK, Amaratunga GAJ, Legagneux P, Gangloff L, Schnell JP, Semet V, Thien VB, Groening O (2004) Carbon nanotubes as field emission sources. J Mater Chem 14:933-943. doi: $10.1039 / \mathrm{b} 314155 \mathrm{c}$

Nagaraju N, Konya Z, Fonseca A, Nagy JB (2002) Alumina and silica supported metal catalysts for the production of carbon nanotubes. J Mol Catal A Chem 181:57-62. doi:10.1016/S1381$1169(01) 00375-2$

Seifi M (2011) Dependence of pore size on catalyst concentration used in synthesis carbon nanotubes. Phys E 43:998-1001. doi: 10.1016/j.physe.2010.11.034

Su M, Zheng B, Liu J (2000) A scalable CVD method for the synthesis of single-walled carbon nanotubes with high catalyst productivity. Chem Phys Lett 322:321-326. doi:10.1016/S00092614(00)00422-X

Wang Y, Shi Z, Yin J (2010) Unzipped multiwalled carbon nanotubes for mechanical reinforcement of polymer composites. J Phys Chem C 114:19621-19628. doi:10.1021/jp107151e 